\title{
WAVE PROPAGATION ON A FLUME: NUMERICAL SIMULATION
}

\author{
J. M. P. Conde ${ }^{\mathrm{a}, \mathrm{b}}$, \\ P. T. S. Roberto ${ }^{\mathrm{a}}$, \\ and C. J. E. M. Fortes \\ ${ }^{\mathrm{a}}$ Universidade Nova de Lisboa \\ Faculdade de Ciências e Tecnologia \\ Unidade de Investigação e Desenvolvimento \\ em Engenharia Mecânica e Industrial \\ Campus de Caparica \\ 2829-516 Monte de Caparica, Portugal \\ jpc@fct.unl.pt \\ ${ }^{\mathrm{b}}$ National Laboratory for Civil Engineering \\ Hydraulics and Environment Department \\ Harbours and Maritime Structures Division \\ Av. do Brasil, 101 \\ 1700-066 Lisbon, Portugal \\ Received: March 04, 2015 \\ Revised: April 06, 2015 \\ Accepted: May 07, 2015
}

ABSTRACT

This paper presents the numerical simulations done by using the waves2Foam, an OpenFOAM ${ }^{\circledR}$ library, to simulate the propagation of regular waves without breaking in a three-dimensional flume. The numerical code solves the unsteady Navier-Stokes equations and uses a Volume-of-Fluid (VoF) method to identify the free-surface. A regular incident wave with a $1.5 \mathrm{~s}$ period and $0.1 \mathrm{~m}$ wave height was considered. This is one of the conditions, from the wide range of wave flume tests conducted at the National Laboratory for Civil Engineering (LNEC), whose objective was to analyze the hydrodynamics of wave transformation and wave breaking for different incident conditions over a variable bathymetry. Comparisons are made between the numerical and the experimental results. These comparisons include time-series of wave-gauges records at several locations along the flume and the corresponding amplitude spectra; significant wave height and average period evolution along the flume; time-series of the velocity components at one section of the flume, measured at the middle of the water column; and hodograph representation of the velocity components, in the middle of the water column, in the $\mathrm{xy}, \mathrm{xz}$, and yz planes, along the flume. It was found that the numerical results obtained are close to the experimental data. The observed differences are attributable to numerical inaccuracies as well as the differences between the wave generation method in the numerical and experimental tests.

Keywords: free-surface, wave propagation, numerical simulation, navierstokes, OpenFOAM

\section{NOMENCLATURE}

a wave amplitude, $\mathrm{m}$

d water depth, $m$

f wave frequency, $\mathrm{Hz}$

g acceleration due to gravity, $\mathrm{m} / \mathrm{s}^{2}$

$\mathrm{H}$ wave height, $\mathrm{m}$

$\mathrm{k}$ turbulent kinetic energy, $\mathrm{m}^{2} / \mathrm{s}^{2}$

$\mathrm{p} \quad$ pressure in excess of the hydrostatic, $\mathrm{Pa}$

$\mathrm{T}$ wave period, $\mathrm{s}$

u velocity, $\mathrm{m} / \mathrm{s}$

$\mathrm{u}, \mathrm{v}, \mathrm{w}$ longitudinal, transversal and vertical Cartesian velocity components, $\mathrm{m} / \mathrm{s}$

$\mathrm{x}, \mathrm{y}, \mathrm{z}$ longitudinal, transversal and vertical Cartesian coordinates, $\mathrm{m}$

\section{Greek symbols}

$\alpha \quad$ Volume-of-Fluid scalar field

$\eta \quad$ free-surface elevation, $\mathrm{m}$

$\kappa_{\alpha} \quad$ surface curvature, $\mathrm{m}^{-1}$

$\mu \quad$ dynamic molecular viscosity, $\mathrm{kg} /(\mathrm{s} \cdot \mathrm{m})$

$\mu_{\mathrm{t}} \quad$ dynamic eddy viscosity, $\mathrm{kg} /(\mathrm{s} \cdot \mathrm{m})$

$\rho$ density, $\mathrm{kg} / \mathrm{m}^{3}$

$\sigma_{\mathrm{T}} \quad$ surface tension coefficient, $\mathrm{kg} / \mathrm{s}^{2}$

$\tau \quad$ specific Reynolds stress tensor, $\mathrm{m}^{2} / \mathrm{s}^{2}$

\author{
Subscripts

$\begin{array}{ll}\text { av } & \text { average } \\ \mathrm{p} & \text { peak } \\ \mathrm{r} & \text { relative } \\ \mathrm{ref} & \text { reference } \\ \mathrm{s} & \text { significant }\end{array}$

\section{INTRODUCTION}

The knowledge of wave transformation and wave-breaking characteristics near the coastline is essential for nearshore hydrodynamics studies (e.g., coastal sediment dynamics), for the design of coastal and port structures, and for estimating forces on pipelines crossing the surf zone. Physical models and laboratory experiments are an important part of the research methodology for acquiring a better knowledge and characterization of these phenomena. Also, the validation of the numerical models depends greatly on accurate, complete and reliable experimental data.

Following this reasoning, a wide range of wave flume tests was performed at the National Laboratory for Civil Engineering (LNEC) to study wave transformation and wave breaking considering different incident conditions. Okamoto et al. (2010) Endres et al. (2011), Neves et al. (2011, 2012) and 
Conde et al. (2012b), performed a set of experimental tests for incident regular wave conditions with and without wave breaking, considering different bottom slopes. Conde et al. (2013a, 2013b, 2013c) followed the methodology of these previous works, considering incident bichromatic and irregular waves.

Different types of data analysis (time analysis; Fourier transform spectral analysis; wavelet transform spectral analysis; and hodograph representation) may be used to characterize the nonlinear phenomena and the harmonic generation due to shoaling and wave breaking. Some of these techniques may be applied to wave-gauges records and/or to Acoustic Doppler Velocimetry (ADV) records. Conde et al. (2014a, 2014b), compared these methods applying them to different types of waves (monochromatic, bichromatic and irregular). The analysis of the velocity data, through these methodologies, illustrates other relevant phenomena occurring in the wave propagation, which cannot be depicted by the usual wave gauges. Each of these techniques has advantages and drawbacks, and so they should be used complementary.

In the framework of coastal engineering, the numerical codes are traditionally based on Boussinesq type equations, e. g., the COULWAVE model (Lynett and Liu, 2009). Recently, due to the increased computational power, the codes that solve the Reynolds-averaged Navier-Stokes (RANS) equations have become of more widespread use. The RANS equations have the advantage of enabling the calculation of, e. g., the characteristics of the turbulence occurring in the surf zone and the efforts resulting from wave impacts on coastal structures.

Among the various numerical codes that allow solving the RANS equations, OpenFOAM ${ }^{\circledR}$ (Open Field Operation and Manipulation) code has gained popularity. This code is composed of a software package (libraries), free of charge and open source, which can be used for Computational Fluid Dynamics (CFD) problem solving, among others (OpenFOAM, 2014). It is developed by OpenCFD Ltd. (ESI Group) and distributed by the OpenFOAM ${ }^{\circledR}$ Foundation. Because it is under the GNU General Public License, the user has complete freedom to run, adapt, redistribute and improve OpenFOAM ${ }^{\circledR}$.

One of the codes, based on OpenFOAM ${ }^{\circledR}$, that has been developed recently to solve coastal engineering problems, is the waves2Foam library (Jacobsen et al., 2012). It has the potential to solve the majority of the problems associated with wave propagation and coastal structure interaction.

The objective of the present work is to evaluate the performance of waves2Foam by comparing its results (free surface and velocities) with the experimental ones of Conde et al. (2012b).

This paper starts with a short description of the experimental layout, the incident wave conditions, the experimental procedures, the numerical code, and the numerical simulation conditions.
Experimental (Conde et al., 2012b) and corresponding numerical simulation data, and results from time and spectral analysis, are presented for an incident regular wave with a period, $\mathrm{T}$, equal to $1.5 \mathrm{~s}$ and wave height, $\mathrm{H}$, equal to $0.1 \mathrm{~m}$. These results include: free surface elevation at five sections along the flume and the corresponding amplitude spectra; significant wave height, $\mathrm{H}_{\mathrm{s}}$, and average period, $\mathrm{T}_{\mathrm{av}}$, along the flume; velocity components at one section of the flume, measured at the middle of the water column; hodograph representation of the velocity components, in the middle of the water column, in the $x y, x z$, and $y z$ planes, along the flume.

\section{EXPERIMENTS}

The experimental tests were performed in the wave flume presented in Figures 1 and 2. This flume, build in the 1950s, has a reduction of width and depth in order to increase regular wave heights and to improve the hydraulic behaviour, by preventing unwanted transversal waves. Nowadays, the flume is equipped with a piston-type irregular wave-maker system controlled by an A/D converter and a personal computer. This wave-maker can generate regular or irregular waves, and is equipped with a reflectedwave dynamic-absorption system (Capitão and Conde, 2012).

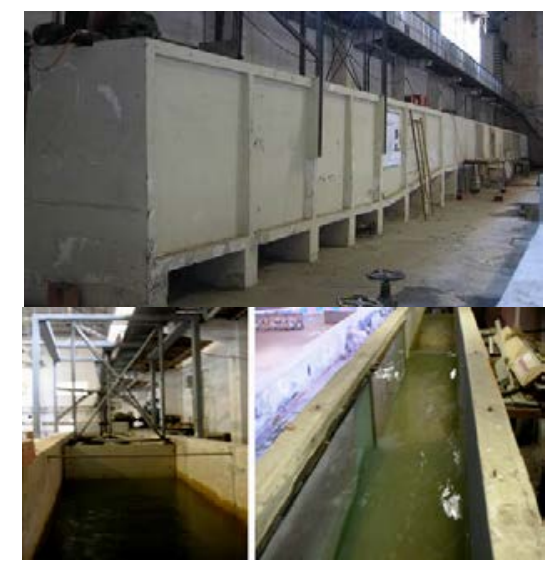

Figure 1. Wave flume.

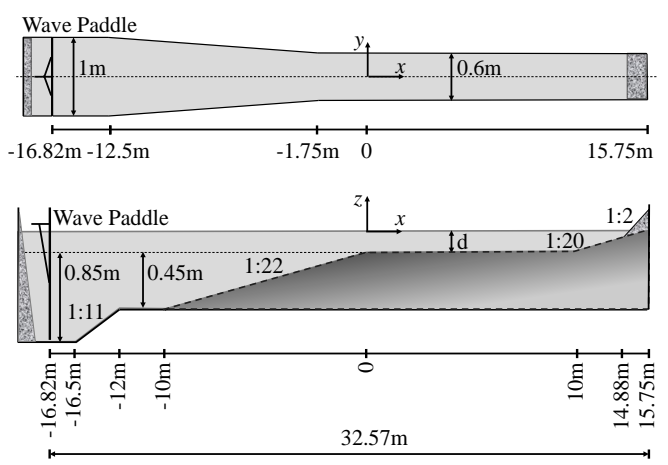

Figure 2. Wave flume’s plan and longitudinal-section views. 
The impermeable bottom is composed by a $10 \mathrm{~m}$ long 1:22 slope ramp, followed by a $10 \mathrm{~m}$ horizontal stretch, then by a 1:20 slope, ending at a 1:2 slope gravel beach which extends above water level. Horsehair sheets were installed over the 1:20 slope to reduce wave reflection.

Experiments were made in three main phases, corresponding to different wave conditions:

a) Regular waves with one of four wave periods $(\mathrm{T}=1.1 \mathrm{~s}, 1.5 \mathrm{~s}, 2.0 \mathrm{~s}$, or $2.5 \mathrm{~s})$ and one of six wave heights $(\mathrm{H}=0.08 \mathrm{~m}, 0.10 \mathrm{~m}, 0.12 \mathrm{~m}, 0.14 \mathrm{~m}, 0.16 \mathrm{~m}$, or 0.18m) (Okamoto et al., 2010, Endres et al., 2011, Neves et al., 2011, 2012, Conde et al., 2012b);

b) Bichromatic waves considering a combination of two regular waves $(\mathrm{T}=1.1 \mathrm{~s}$ and $1.5 \mathrm{~s})$ with the same wave height $(\mathrm{H}=0.06 \mathrm{~m}$ or $0.08 \mathrm{~m})$ (Conde et al., 2013a, 2013b);

c) Irregular waves (JONSWAP spectrum) with: peak period $T_{p}=1.5 \mathrm{~s}$ and one of four different significant wave heights $\left(\mathrm{H}_{\mathrm{s}}=0.12 \mathrm{~m}, 0.14 \mathrm{~m}, 0.16 \mathrm{~m}\right.$, or $0.18 \mathrm{~m}) ; \mathrm{T}_{\mathrm{p}}=2.0 \mathrm{~s}$ with $\mathrm{H}_{\mathrm{s}}=0.14 \mathrm{~m}$; and $\mathrm{T}_{\mathrm{p}}=2.5 \mathrm{~s}$ with $\mathrm{H}_{\mathrm{s}}=0.14 \mathrm{~m}$ (Conde et al., 2013c).

For selected wave conditions two different water depths in the horizontal stretch (Fig. 2) were considered, $\mathrm{d}=0.1 \mathrm{~m}$ and $0.3 \mathrm{~m}$, in order to have wave breaking and non-breaking conditions, respectively.

Details about the wave generation procedure may be found in Conde et al. (2012b, 2013a, 2013c). The dynamic-absorption for reflected-waves system was not activated, so that the waves would always be generated in the same manner for all the experimental tests, preventing automatic corrections by the wave maker that might be different from test to test.

The reflection coefficient was evaluated by the Mansard and Funke (1980) method, considering regular and irregular waves, for a water depth $d=0.3 \mathrm{~m}$ corresponding to non-breaking wave condition (Capitão and Conde, 2012, Conde et al., 2012a). For regular waves with $\mathrm{T}=1.5 \mathrm{~s}$ and $\mathrm{H}=0.06 \mathrm{~m}, 0.08 \mathrm{~m}$ or $0.1 \mathrm{~m}$, the reflection coefficient is around 0.15 . For this water depth $(\mathrm{d}=0.3 \mathrm{~m})$ these regular waves only break at the end of the flume over the porous blankets. The reflection coefficient increases with the wave period from around 0.05 , for $\mathrm{T}=1.1 \mathrm{~s}$, to around 0.3 , for $\mathrm{T}=2.5 \mathrm{~s}$, considering $\mathrm{H}=0.08 \mathrm{~m}$ or $0.1 \mathrm{~m}$. Waves with $\mathrm{H}=0.12 \mathrm{~m}$ and higher, for $\mathrm{d}=0.3 \mathrm{~m}$, break before the beginning of the horizontal zone. For $\mathrm{d}=0.1 \mathrm{~m}$, all tested waves (regular, bichromatic and irregular) break before this zone; the remaining wave energy is then dissipated in the blankets over a 1:20 slope.

Free-surface elevations were measured using an eight-gauge movable-structure, $1.8 \mathrm{~m}$ long (Fig. 3 left), with gauges positioned $0.2 \mathrm{~m}$ apart. This structure was placed at different locations along the flume, and measurements were taken from $x=-10 m$ up to $x=10 \mathrm{~m}$. A reference wave-gauge was installed near the wave-maker at $x=-10.8 \mathrm{~m}$, in order to verify the input wave height. The three-orthogonal velocity components were measured by an ADV probe.
Together with the ADV probe, a resistive gauge was placed in the same cross section for simultaneous measurements of the free-surface elevation (Figure 3 - right). The ADV probe was located in the longitudinal symmetry-plane of the flume and at middepth of the water column, and measurements were obtained between $\mathrm{x}=-10 \mathrm{~m}$ and $\mathrm{x}=7 \mathrm{~m}$, with a $1 \mathrm{~m}$ interval. Vertical profiles of longitudinal velocity component were obtained at selected sections along the flume. The sampling frequency of all measurements was $25 \mathrm{~Hz}$ and each run (incident wave) had a useful duration of 240s for regular and bichromatic and 190s for irregular waves.

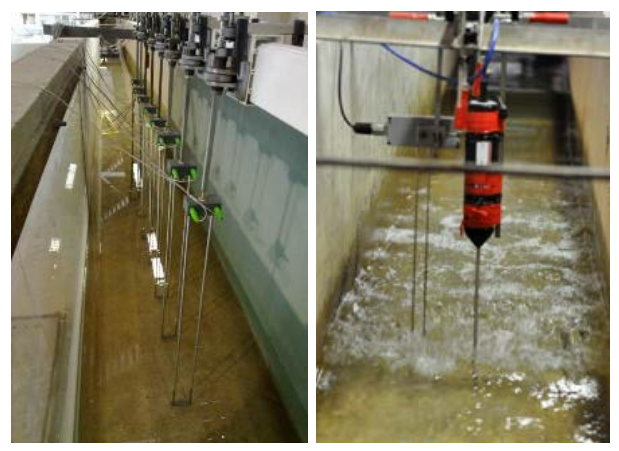

Figure 3. Eight wave-gauge mobile-structure (left) and ADV probe with a wave-gauge (right).

\section{NUMERICAL SIMULATIONS}

The numerical results presented were all obtained by using the waves2Foam library (Jacobsen et al., 2012). This is a toolbox used to generate and absorb free-surface water waves. The method applies a relaxation-zone technique (active sponge-layers) to generate and absorb surface-waves and a large range of wave theories are supported. This solver is based on the original implementation of interFoam, which is a solver for two incompressible fluids that tracks the interface using the Volume-of-Fluid (VoF) method. The simulations were performed using OpenFoam v. 2.2.1, installed on Ubuntu 12.04 LTS.

$$
\begin{gathered}
\frac{\partial \rho \mathbf{u}}{\partial \mathrm{t}}+\nabla \cdot\left[\rho \mathbf{u u}^{\mathrm{T}}\right]= \\
-\nabla \cdot \mathrm{p}-\mathbf{g} \cdot \mathbf{x} \nabla \rho+\nabla \cdot[\mu \nabla \mathbf{u}+\rho \boldsymbol{\tau}]+\sigma_{\mathrm{T}} \kappa_{\alpha} \nabla \alpha \\
\nabla \cdot \mathbf{u}=0 \\
\boldsymbol{\tau}=\frac{2}{\rho} \mu_{\mathrm{t}}\left[\frac{1}{2}\left(\nabla \mathbf{u}+(\nabla \mathbf{u})^{\mathrm{T}}\right)\right]-\frac{2}{3} \mathrm{k} \mathbf{I} \\
\frac{\partial \alpha}{\partial \mathrm{t}}+\nabla \cdot[\mathbf{u} \alpha]+\nabla \cdot\left[\mathbf{u}_{\mathrm{r}} \alpha(1-\alpha)\right]=0 \\
\Phi=\alpha \Phi_{\text {Water }}+(1-\alpha) \Phi_{\text {Air }}
\end{gathered}
$$


The governing equations for the combined flow of air and water are the RANS equations, Eq. (1), and the continuity equation, Eq. (2), for incompressible flows. These equations are solved for the two immiscible fluids simultaneously, where the fluids are tracked using a scalar field, $\alpha$, which is 0 for air and 1 for water, and any intermediate value is a mixture of the two fluids, so the free surface is defined at $\alpha=0.5$. The distribution of $\alpha$ is modelled by an advection equation, Eq. (4). The spatial variation in any fluid property, $\Phi$, such as $\rho$ and $\mu$, with the content of air/water in the computational cells is obtained through the weighting defined by Eq. (5).

Here, $\mathbf{u}=(\mathrm{u}, \mathrm{v}, \mathrm{w})$ is the velocity field in Cartesian coordinates, $\mathbf{x}=(\mathrm{x}, \mathrm{y}, \mathrm{z}), \mathrm{p}$ is the pressure in excess of the hydrostatic, $\rho$ is the density, $\mathbf{g}$ is the acceleration due to gravity and $\mu$ is the dynamic molecular viscosity. $\tau$ is the specific Reynolds stress tensor, defined in Eq. (3), where $\mu_{t}$ is the dynamic eddy viscosity and $\mathrm{k}$ is the turbulent kinetic energy per unit mass. The last term in Eq. (1) accounts for the effect of surface tension, where $\sigma_{\mathrm{T}}$ is the surface tension coefficient and $\kappa_{\alpha}$ is the surface curvature. The last term on the left-hand side of Eq. (4) is a compression term, which limits the smearing of the interface, and $\mathbf{u}_{\mathrm{r}}$ is a relative velocity. Turbulence may be modelled by, e. g., the Wilcox's k- $\omega$ closure model. The complete details of this solver may be found in Jacobsen et al. (2012).

The discretization mesh, with a total of 322040 finite control volumes, was generated respecting the criteria for the free-surface zone: 10 volumes for wave height; and 50 volumes for wave length. The computational domain spans from $x=-16.82 \mathrm{~m}$, the wave-maker location, up to $\mathrm{x}=10 \mathrm{~m}$, the end of the horizontal stretch (Fig. 2). The wave generation relaxation zone, $6.18 \mathrm{~m}$ long, is located on the left side of computational domain. The wave dissipation relaxation zone, $5.75 \mathrm{~m}$ long, is located on the right side of computational domain. The rest water freesurface is located at $\mathrm{z}=0$, and the top of the computational domain is located at $\mathrm{z}=0.5 \mathrm{~m}$.

The imposed boundary conditions were: No-slip impermeable wall at the bottom and side walls; outlet condition allowing the in- and out-flow of air at the top; and zero gradient to pressure.

The algorithms and numerical schemes used are presented in Tab. 1. Further details about these may be found in OpenFOAM (2014).

\section{RESULTS AND DISCUSSION}

This section presents the comparison of the numerical results obtained for the incident nonbreaking regular wave with $\mathrm{T}=1.5 \mathrm{~s}$ and $\mathrm{H}=0.1 \mathrm{~m}$, for $\mathrm{d}=0.3 \mathrm{~m}$, with the corresponding experimental test results by Conde et al. (2012b). Different types of data analysis were considered: a) Time series of wave gauges records at several locations along the flume and the corresponding amplitude spectra; significant wave height and average period evolution along the flume;

b) Time series of the velocity components at one section of the flume, measured at the middle of the water column; and hodograph representation of the velocity components, in the middle of the water column, in the xy, xz, and yz planes, along the flume.

Table 1. Algorithms and numerical schemes used.

\begin{tabular}{|c|c|}
\hline \multicolumn{2}{|c|}{ Numerical schemes } \\
\hline Euler & Time \\
\hline Gauss & $\begin{array}{l}\text { Divergence } \\
\text { Gradient }\end{array}$ \\
\hline $\begin{array}{l}\text { Gauss Linear } \\
\text { Corrected }\end{array}$ & Laplacian \\
\hline \multicolumn{2}{|c|}{ Interpolation schemes } \\
\hline LimitedLinearV1 & Velocity field \\
\hline MUSCL & Volume fraction \\
\hline InterfaceCompression & $\begin{array}{c}\text { Volume fraction } \\
\text { compression }\end{array}$ \\
\hline \multicolumn{2}{|c|}{ Algorithm } \\
\hline $\begin{array}{c}\text { GAMG Linear- } \\
\text { Solver }\end{array}$ & Pressure \\
\hline PBiCG & $\begin{array}{c}\text { Velocity } \\
\text { Volume fraction }\end{array}$ \\
\hline
\end{tabular}

\section{Free-surface elevation}

Figure 4 presents the numerical results and the wave-gauge data records, at several sections along the flume ( $x=-10,-5,-2,1$ and $5 m)$, during 10 wave periods. Figure 5 presents the amplitude spectra corresponding to data records presented in Fig. 4. These amplitude spectra were calculated using a discrete-time Fourier transform. The experimental reference value for the amplitude, $a_{\text {ref }}$, is half of the significant wave height at the reference wave gauge $(x=-10.8 \mathrm{~m}), H_{s \text { ref }}=0.119 \mathrm{~m}$. The numerical reference value for this amplitude is $0.05 \mathrm{~m}$.

From these figures one can observe a clear wave transformation as it propagates to areas of lower depths. The deformed of the free-surface presents increasingly non-linear characteristics (sharp crests and elongated troughs). The results from this analysis show that, as the wave propagates to shallower zones, the harmonics amplitudes, virtually inexistent at the beginning of the slope, become more important. The increase in the amplitude of the main frequency, due to the shoaling effect, as the wave propagates in the main slope is also visible. The numerical results follow the main behaviour of the experimental ones, but presents some numerical dissipation, more visible, at $x=5 m$, by the reduction of amplitude of the main frequency and the harmonics. Tab. 2 presents the amplitude values for the main frequency and the harmonics presented in Fig. 5. 

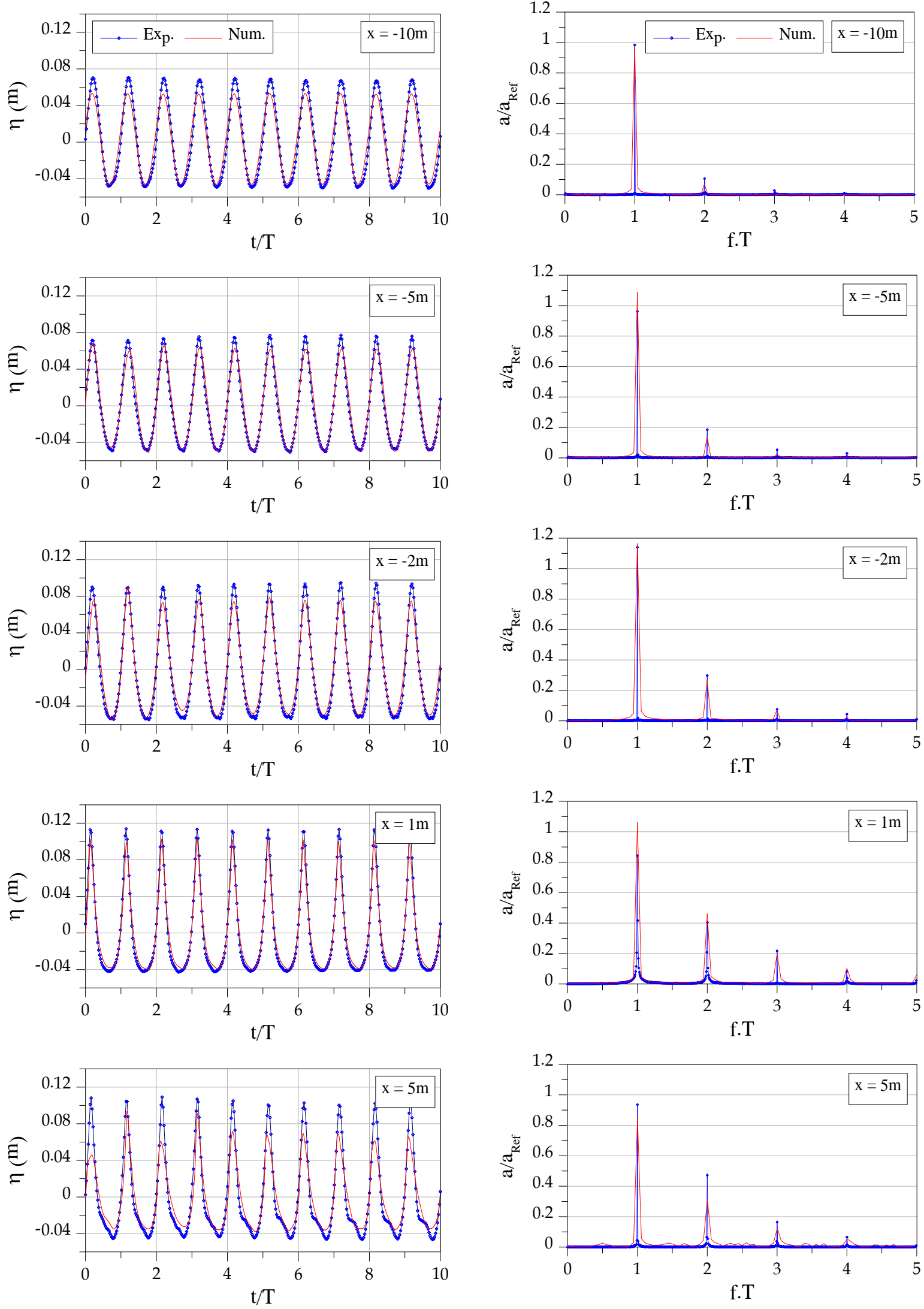

Figure 4. Experimental and numerical free-surface elevation time-series, $\eta$, for a regular incident wave ( $\mathrm{T}=1.5 \mathrm{~s}$ and $\mathrm{H}=0.1 \mathrm{~m}$, for $\mathrm{d}=0.3 \mathrm{~m}$ ), at different sections, $\mathrm{x}$, along the flume.

Figure 5. Experimental and numerical amplitude spectra, a, for a regular incident wave ( $T=1.5 \mathrm{~s}$ and $\mathrm{H}=0.1 \mathrm{~m}$, for $\mathrm{d}=0.3 \mathrm{~m}$ ), at different sections, $\mathrm{x}$, along the flume. 
Table 2. Amplitude spectra values.

\begin{tabular}{|c|c|c|c|c|c|}
\hline \multicolumn{7}{|c|}{ Experimental } \\
\hline f.T & 1 & 2 & 3 & 4 & x(m) \\
\hline \multirow{4}{*}{ a $_{\text {ref }}$} & 0.984 & 0.106 & 0.0279 & 0.0107 & -10 \\
\cline { 2 - 6 } & 0.962 & 0.185 & 0.053 & 0.0298 & -5 \\
\cline { 2 - 6 } & 1.14 & 0.297 & 0.0757 & 0.0436 & -2 \\
\cline { 2 - 6 } & 0.84 & 0.405 & 0.217 & 0.0818 & 1 \\
\cline { 2 - 6 } & 0.936 & 0.472 & 0.165 & 0.0653 & 5 \\
\hline \multicolumn{6}{|c|}{ Numerical } \\
\hline f.T & 1 & 2 & 3 & 4 & x(m) \\
\hline \multirow{4}{*}{ a/a ref } & 0.978 & 0.0697 & 0.0071 & 0.0004 & -10 \\
\cline { 2 - 6 } & 1.09 & 0.141 & 0.0229 & 0.0045 & -5 \\
\cline { 2 - 6 } & 1.16 & 0.264 & 0.0299 & 0.0208 & -2 \\
\cline { 2 - 6 } & 1.06 & 0.460 & 0.1986 & 0.1024 & 1 \\
\cline { 2 - 6 } & 0.852 & 0.315 & 0.125 & 0.0546 & 5 \\
\hline
\end{tabular}

Figure 6 shows the numerical and the experimental values of the significant wave height, $\mathrm{H}_{\mathrm{s}}$, and the average wave period, $\mathrm{T}_{\mathrm{av}}$, evolution along the flume. This figure shows an increase of experimental $\mathrm{H}_{\mathrm{s}}$ throughout the flume up to $\mathrm{x}=0$ due to the shoaling effect. For $x>0$ the significant wave height is essentially the same, but some oscillations on the wave height values are also observed, which may be due to wave reflection at the end of the flume. The experimental tests also show that, although there is a generation of higher order harmonics (Figure 5), the average wave period remains approximately constant throughout the flume.
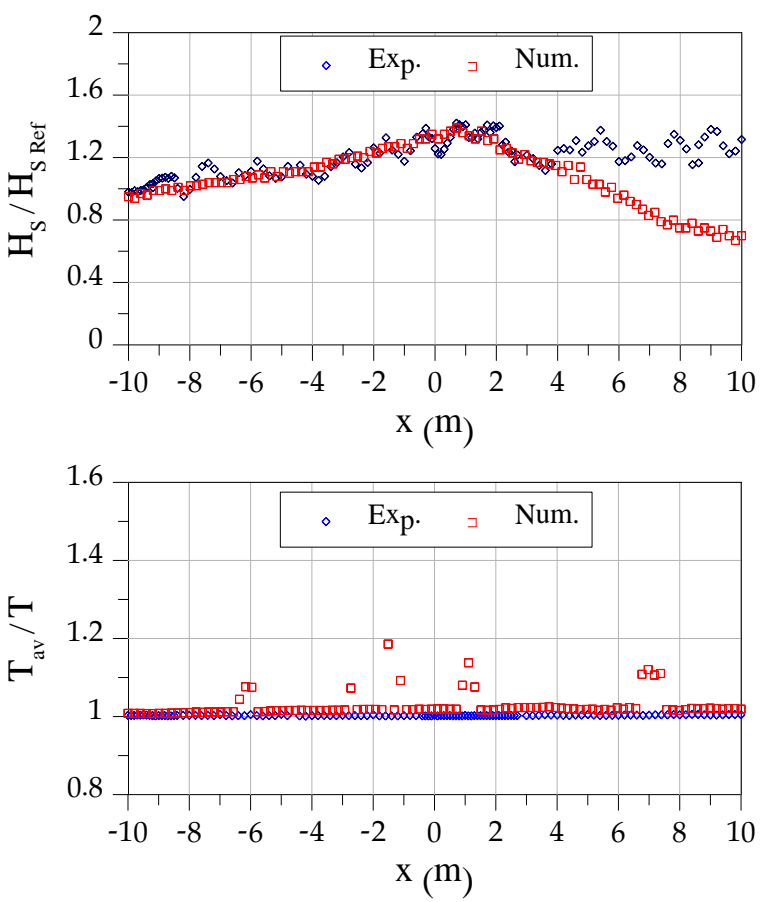

Figure 6. Experimental and numerical significant wave height, $\mathrm{H}_{\mathrm{s}}$, and wave average period, $\mathrm{T}_{\mathrm{av}}$, along the flume, for a regular incident wave $(\mathrm{T}=1.5 \mathrm{~s}$ and $\mathrm{H}=0.1 \mathrm{~m}$, for $\mathrm{d}=0.3 \mathrm{~m})$.

The numerical values of $\mathrm{H}_{\mathrm{s}}$ increase up to $x=1 m$, after this section the value decreases at a constant rate, which may be a consequence of numerical wave breaking. This wave condition is near the experimental wave breaking condition. It is also visible that the numerical solution doesn't present the oscillations due to reflection as the experimental one does; this is consequence of the effective numerical dissipation zone.

The numerical average period, unlike the experimental one, presents some oscillations along the flume. This may be due to the numerical acquiring rate of $5 \mathrm{~Hz}$, lower than the $25 \mathrm{~Hz}$ used in the experimental results. This inferior value of acquiring rate produces a less accurate result in the period evaluation, and was used due to computer storage limitations.

\section{Velocity}

Figure 7 presents the comparison of the numerical results and the experimental data for the velocity components time series, at the position $\mathrm{x}=-10 \mathrm{~m}, \mathrm{y}=0$, and $\mathrm{z}=-0.15 \mathrm{~m}$, during 10 wave periods.
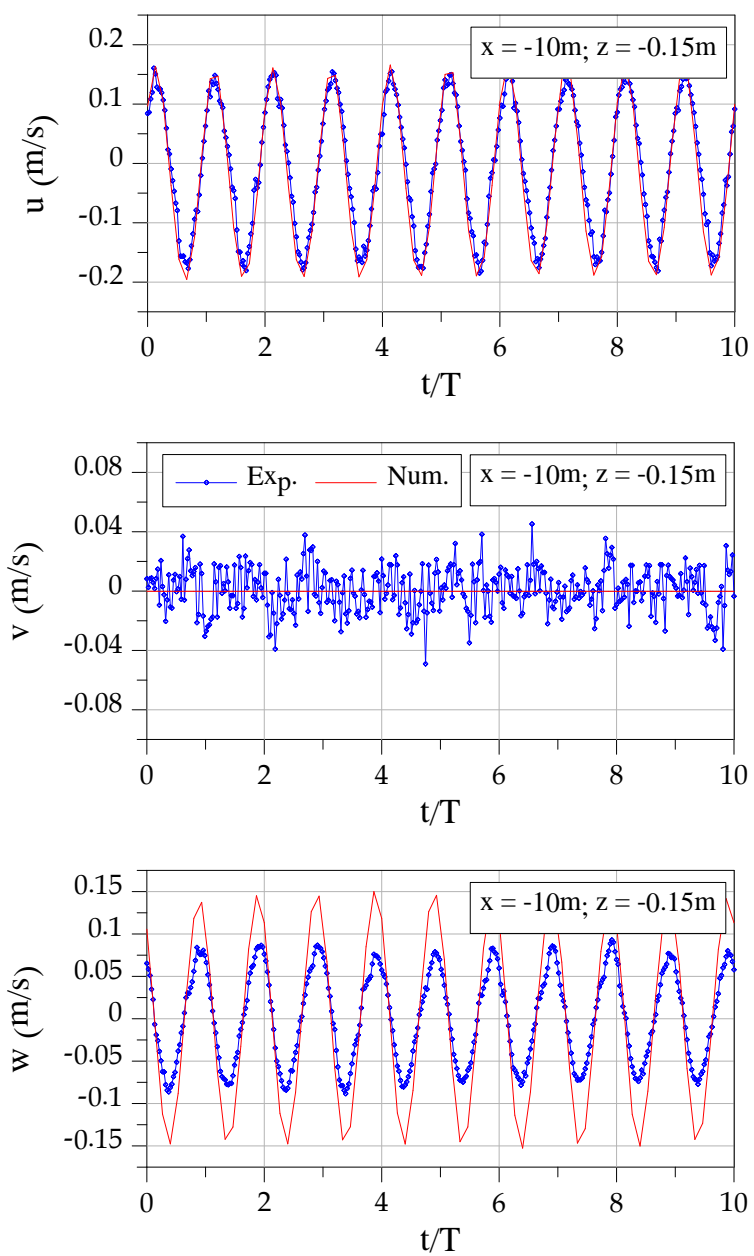

Figure 7. Experimental and numerical velocity components time series, at the position $\mathrm{x}=-10 \mathrm{~m}, \mathrm{y}=0$, and $\mathrm{z}=-0.15 \mathrm{~m}$. 
It is visible that: for the $\mathrm{u}$ component the numerical results are very similar to the experimental ones; unlike the experimental data, the numerical $\mathrm{v}$ component is almost zero, as it would be expected, due to the way the numerical wave was generated; the numerical $\mathrm{w}$ component presents values larger than the experimental ones and similar to the $\mathrm{u}$ component, showing that the simulated wave presents characteristics different and more linear than the experimental wave.

Figure 8 presents the hodograph representation of the experimental and the numerical recorded data clouds distribution at $\mathrm{x}=-10 \mathrm{~m}, \mathrm{y}=0$ and $\mathrm{z}=-0.15 \mathrm{~m}$. It is visible a distorted elliptical shape in the $\mathrm{xz}$ plane with a dispersion of points around its average line for the experimental data and circular shape for the numerical data. A dispersion of points around zero is also visible in the $\mathrm{xy}$ and $\mathrm{yz}$ planes, for the experimental data, this is a consequence of the $\mathrm{v}$ component fluctuation around zero; the numerical representation doesn't present such behavior because $\mathrm{v}$ is almost zero.
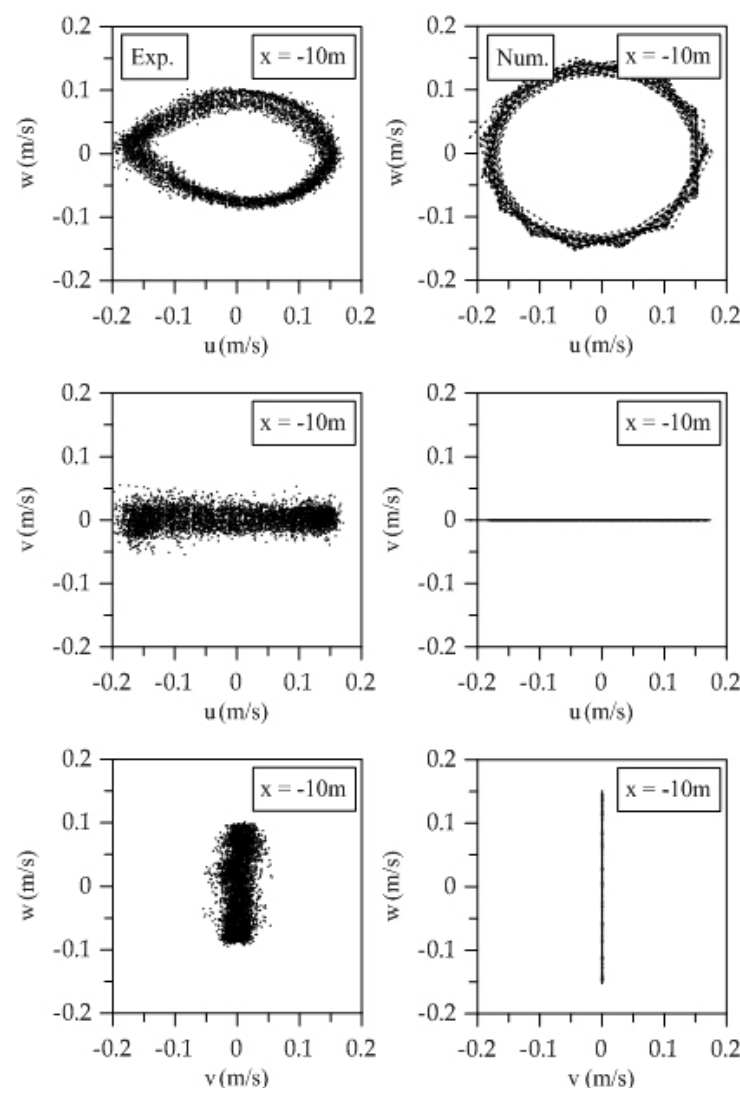

Figure 8. Experimental and numerical hodograph of the velocity components: recorded data cloud at $\mathrm{x}=-10 \mathrm{~m}, \mathrm{y}=0$ and $\mathrm{z}=-0.15 \mathrm{~m}$.

Figure 9 presents the experimental and numerical data clouds evolution, in the $\mathrm{xz}$ plane, along the longitudinal axis at different $x$ locations with $y=0$ and $z=-0.15 m$. Figure 9a) shows, for the experimental data, that as $\mathrm{x}$ increases, the elliptical shape becomes larger and the aspect ratio changes (e. g., flatten ellipse at $\mathrm{x}=-2 \mathrm{~m}$ ), this is a direct consequence of the shoaling effect. Figure 9b) shows, for the numerical data, that as $\mathrm{x}$ increases, the shape starts as a circle and changes to an ellipse. However, the ellipses are different in the experimental and the numerical representation, particularly for $u$ negative and $\mathrm{w} \sim 0$.

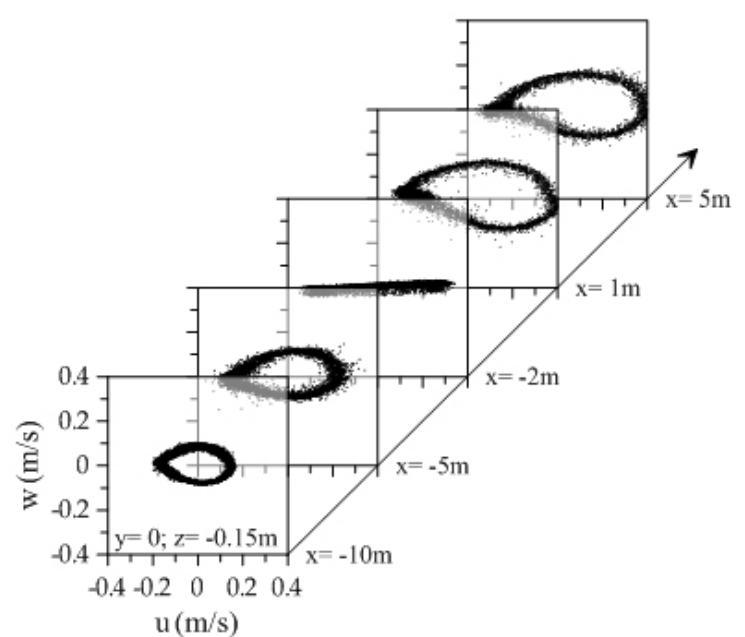

a)

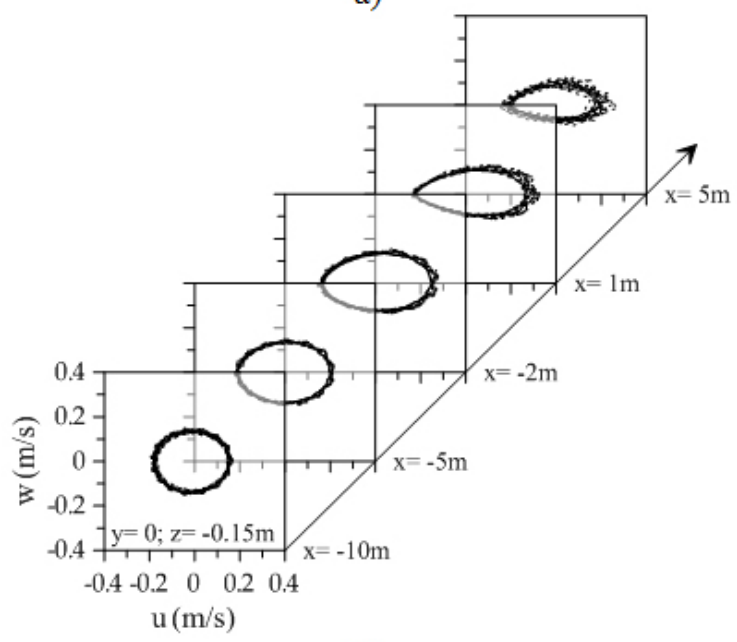

b)

Figure 9. Hodograph of the velocity components: Experimental (a) and numerical (b) recorded data clouds evolution along the longitudinal axis at different locations with $\mathrm{y}=0$ and $\mathrm{z}=-0.15 \mathrm{~m}$.

\section{CONCLUSIONS}

The main conclusions that can be obtained from this study are:

a) The numerical results follow the main behaviour of the experimental ones, but present some numerical dissipation, which is visible in the timeseries graphics and by the reduction of amplitude of the main frequency and its harmonics. The significant wave height evolution along the flume shows that the numerical wave breaks, unlike the experimental wave. These results may be improved by the use of a 
more refined mesh and/or different numerical schemes.

b) The velocity time-series, complemented by the hodograph representation, allow us to conclude that, although the free-surface gauges data show similar behaviour between experimental and numerical results, there are important differences between both results. The numerical wave generation method produced a linear wave that differs from the non-linear wave produced by the piston-type physical wave-maker. These differences are visible at all sections along the flume.

As a conclusion, one can say that the observed differences between the numerical and the experimental results are attributable to numerical inaccuracies as well as to the different wave generation method in the numerical and experimental tests.

\section{ACKNOWLEDGEMENTS}

The experimental data presented was obtained at LNEC within the scope of the J. M. P. Conde sabbatical leave from Universidade Nova de Lisboa (Portugal). The support by the FCT projects DITOWEC (PTDC/ECM-HID/1719/2012) and HIDRALERTA (PTDC/AAC-AMB/120702/2010) is acknowledged.

\section{REFERENCES}

Capitão, R., and Conde, J. M. P., 2012, Implementing the Awasys Wave Absorption System in a Peculiar Wave Flume, in: 4th International Conference on the Application of Physical Modelling to Port and Coastal Protection - Coastlab12, Ghent, Belgium.

Conde, J. M. P., Capitão, R., Neves, M. G., and Fortes, C. J. E. M., 2012a, Comparison of Various Techniques of Passive Absorption of Waves with Assessment of Incident and Reflected Agitation in a Wave Flume, in: 2nd Hydrographic Engineering Workshop, Hydrographic Institute, Lisbon, Portugal, pp. 131-134.

Conde, J. M. P., Reis, R., Fortes, C. J. E. M., and Neves, D. R. C. B., 2012b, Wave Propagation on a Flume: Physical Modelling, Thermal Engineering, Vol. 11, pp. 22-29.

Conde, J. M. P., Fortes, C. J. E. M., Didier, E., Lemos, R., and Reis, R., 2013a, Physical Modelling of Bichromatic Wave Propagation and Wave Breaking in a Wave Flume, in: 6th SCACR International Short Course/Conference on Applied Coastal Research, Lisbon, Portugal.

Conde, J. M. P., Fortes, C. J. E. M., Didier, E., Lemos, R., and Reis, R., 2013b, Physical Modelling of Bichromatic Waves with and without Wave Breaking, in: Congress of Numerical Methods in Engineering, Bilbao, Spain.
Conde, J. M. P., Fortes, C. J. E. M., Lemos, R., Reis, R., 2013c, Physical Modelling of Irregular Waves with Wave Breaking, in: 8th Portuguese Workshop on Coastal and Port Engineering, Lisbon, Portugal.

Conde, J. M. P., Lemos, R., and Fortes, C. J. E. M., 2014a, Comparison between Time, Spectral and Wavelet Analysis on Wave Breaking and Propagation, in: 3rd IAHR Europe Congress, Porto, Portugal.

Conde, J. M. P., Neves, C. F., Fortes, C. J. E. M., and Lemos, R., 2014b, Experimental Wave Breaking Velocity Characterization for Monochromatic, Bichromatic and Irregular Waves, in: 5th International Conference on the Application of Physical Modelling to Port and Coastal Protection - Coastlab14, Varna, Bulgaria.

Endres, L., Neves, D. R. C. B., Didier, E., Fortes, C. J. E. M., and Okamoto T., 2011, Performance Evaluation of Numerical Models to Simulate Waves Along a Wave Channel, in: Congress of Numerical Methods in Engineering (CMNE2011), Coimbra, Portugal.

Jacobsen, N. G., Fuhrman, D. R., and Fredsøe, J., 2012, A Wave Generation Toolbox for the Opensource CFD Library: OpenFoam $\AA$, International Journal of Numerical Methods in Fluids, Vol. 70, pp. 1073-1088.

Lynett, P., and Liu, P. L.-F., 2009, Modeling Wave Generation, Evolution, and Interaction with Depth-Integrated, Dispersive Wave Equations COULWAVE Code Manual Cornell University Long and Intermediate Wave, Modeling Package v. 2.0.

Mansard, E. P. D., and Funke, E. R., 1980, The Measurements of Incident and Reflected Spectra using a Least Squares Method, in: 17th International Conference of Coastal Engineering, Sidney, Australia, pp.154-172.

Neves, D. R. C. B., Endres, L., Fortes, C. J. E. M., and Okamoto T., 2011, Physical Modelling of Wave Propagation and Wave Breaking in a Wave Channel, in: 5th SCACR International Short Conference on Applied Coastal Research, Aachen, Germany.

Neves, D. R. C. B., Endres, L. A. M., Fortes, C. J. E. M., and Okamoto, T, 2012, Directional Spreading Model in a Wave Channel: Wave Propagation and Wave Breaking, Ocean Engineering, Vol. 55, pp. 148-160.

Okamoto, T., Fortes, C. J. E. M., and Basco, D. R., 2010, Bore Propagation Speed at the Termination of Wave Breaking, in: 32nd International Conference on Coastal Engineering, Shanghai, China.

OpenFOAM, 2013, OpenFOAM - The Open Source CFD Toolbox User Guide, Version 2.2.1, OpenCFD. 